\title{
Sustaining Teacher Control in a Blog-Based Personal Learning Environment
}
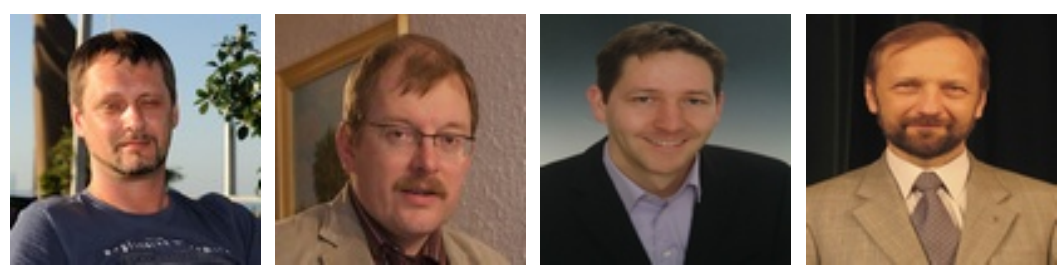

Vladimir Tomberg, Mart Laanpere, Tobias Ley, and Peeter Normak Tallin University, Estonia

\section{Abstract}

Various tools and services based on Web 2.0 (mainly blogs, wikis, social networking tools) are increasingly used in formal education to create personal learning environments, providing self-directed learners with more freedom, choice, and control over their learning. In such distributed and personalized learning environments, the traditional role of the teacher is being transformed into that of a facilitator. This change inevitably means a reduced level of control on the part of the teacher. This is evidenced, for example, in difficulties experienced in retaining the necessary levels of control when the learning process moves away from institutionally maintained systems to blog-based personal learning environments. In conducting a course in a formal education setting however, it is still essential for the teacher to retain control over certain learning activities, such as course enrolment, assignments, and the assessment process.

A course management plug-in for the WordPress blog platform called LePress was designed and developed as a possible solution to this problem. By using LePress, teachers are able to more easily manage and coordinate courses in a distributed blogbased environment. Teachers are able to regain control over some important aspects of online course management, while maintaining the learners' freedom and choice for selfdirected learning. This paper documents the results of a survey of a group of 37 teachers who used LePress for at least six months. The study demonstrates that by using LePress, teachers experienced an enhanced level of control over several aspects of the course and this reinforced their perception about the ease of use of the system.

Keywords: Teacher control; PLE; LMS; blog-based learning; perceived easy to use 


\section{Introduction}

In the formal education context, technology-enhanced learning is usually conducted with the help of an institutional learning management system (LMS). Modern learning management systems provide teachers and learners with a set of tools for sharing learning resources, communicating within a study group, course enrolment, assignments, tests, assessments, activity monitoring, and other types of learning or course management activities. Learning management systems provide a secure and highly structured online learning environment, supporting various types of pedagogical approaches. In spite of this, learners and teachers increasingly adopt new types of webbased tools such as blogs and wikis, which are not hosted, provided by, or even recommended by the university. Users are attracted to such tools because they often have higher levels of user participation, openness, and network effects (Zourou, 2012), and often offer high quality learning resources (Ullich et al., 2008). While some studies reflect enthusiasm about the use of Web 2.0 tools by teachers and learners (Lee \& McLoughlin, 2007; Redecker, Ala-Mutka, Bacigalupo, Ferrari, \& Punie, 2009; Safran, Helic, \& Gütl, 2007), others are more sceptical about this process. Although they do not deny a growing interest in using Web 2.0 tools in the context of formal education, they call attention to the conflict between the participatory and collaborative nature of Web 2.0 learning and the current structures of formal education (Cole, 2009; Clark, Logan, Luckin, Mee, \& Oliver, 2009; Conole \& Alevizou, 2010; Crook, 2012; Greenhow, Robelia, \& Hughes, 2009).

An opportunity to have more control over one's own learning process and environment is another incentive for using alternative online tools outside of an institutional LMS. By reflecting the hierarchical organizational structures of universities, the LMS is built on a strict top-down approach, giving absolute administrative control to technical specialists in an IT department, while giving less control to the teachers. Steel and Levy have found that integrating the use of the LMS into teacher practices presents a significant challenge in which teachers routinely try to reconcile their internal tacit beliefs with LMS environments (Steel \& Levy, 2009). The students in the LMS are placed at the "bottom rung of the ecological hierarchy" (Dron, 2007): They have only limited opportunities to implement those learning activities, tools, and resources, which have been pre-defined by teachers (McLoughlin \& Lee, 2007; Siemens, 2006). By contrast, when using Web 2.0 tools, a student or teacher is able to build a personal learning environment (PLE), which gives their owners high levels of choice and control over their learning activities.

An example of this kind of environment is a blog-based environment in which students publish reflections about course materials, discuss with others, and submit their assignments through personal weblogs (Pata \& Merisalo, 2009). Another example of adapting blogs as a PLE is demonstrated by the widespread use of blogs as the main personal tool in massive online courses (Fini, 2009; Kop, 2011). Kim (2008) provided several reasons for using blogs instead of traditional computer-mediated communication applications, such as the sense of ownership, the support of both social 
and individual learning, the less intrusive "pull" RSS technology, and the possibility to archive user data (Kim, 2008). As students have control over their personal weblogs, they also have greater control over their learning.

To differentiate the PLE from any other common set of Web 2.0 services, several technical and educational attributes of the PLE can be identified. Among educational attributes, Salinas et al. (2011) proposed considering the ability of students to define learning goals, manage learning content and process, and communicate with others during the learning process (Salinas, Marín, \& Escandell, 2011). According to Attwell (2007), another important feature of the PLE is that it allows learners to configure and develop a learning environment that suits and enables their style of learning (Attwell, 2007). Control by the learner over the choice of learning activities, resources, and tools perfectly corresponds with the self-regulated learning theory (Zimmerman, 1990) and encourages the shift from teacher-centred to learner-centred learning. Yet, the teacher must keep a balance between teacher control and learner autonomy in order to retain the effectiveness of self-regulated learning (Drexler, 2010). Similar arguments have been presented in organizational and workplace learning domains where a balance between individually driven learning and organizational guidance has been captured in concepts of knowledge maturation (Kaschig et al., 2012; Schmidt et al., 2009).

The requirement for combining the LMS and PLE functionalities stems from the different kinds of affordances they offer. While LMS have more affordances for course management, Web 2.0 tools and social media have more affordances for individual expression of students, self-directed learning, expression of ideas, and group collaboration.

One way to achieve this balance is by integrating external Web 2.0 tools with formal LMS, which is increasingly being applied in universities (Dron, 2007; Meccawy, Blanchfield, Ashman, Brailsford, \& Moore, 2008; Sankey \& Huijser, 2009), thanks to powerful APIs of the most popular LMSs. The problem with this approach is that the LMS is still in a dominant role and learners cannot avoid using two completely different environments in parallel.

An alternative scenario is based on conducting learning activities completely outside of the LMS, yet providing enhanced support for course management in Web 2.0 based personal learning environments. For example, one problem in the blog-based scenario referred to above is that getting an overview of all course activities is difficult, and, hence, teachers have no control over the learning environment (Attwell, 2007; Dron, 2007). Consequently, the authors have been researching and developing a software solution that could act as a course coordination space (Wilson, 2007) in blog-based learning environments. The course coordination space was proposed as a lightweight system that sits "between the personal system and the enterprise" (PLE and institution) and introduces a common course related view and semantics in an otherwise distributed PLE environment. For example, the course coordination space can play the role of a central point for gathering data from distributed Web 2.0 tools, provide required 
learning semantics for student's activities (such as course enrolment, homework submission), and provide features for monitoring and analysis (such as a grade book, an overview of students' learning activities). After considering such functionalities, the authors developed a software plug-in called LePress ${ }^{1}$ (Learning with WordPress) for the most popular blogging platform, WordPress. By conducting several design-based research iterations (Tomberg \& Laanpere, 2008, Tomberg \& Laanpere, 2009, Tomberg, Kuli, Laanpere, \& Normak, 2010, Tomberg, Laanpere, \& Lamas, 2010), a balance was achieved between learner autonomy and teacher control in the blog-based personal learning environment. This study presents the final iteration of a major design-based research exercise. The study focused on the following question: Can a dedicated course coordination tool such as LePress sustain the teacher's control over learning management activities in blog-based personal learning environments?

It is important to mention that this research does not suggest all the possible ways for using Web 2.0 tools in the context of education (e.g., group work of students), but concentrates on issues related to a teacher's and individual learner's interactions.

This study begins with a review of recent research on issues related to teacher control and then introduces LePress as a possible solution for improving course coordination in a blog-based PLE. A description of the design of the survey conducted among teachers is presented, followed by a discussion of the survey results.

\section{Teacher Control and the Blog-Based Learning Environment}

\section{Teacher Control}

While the majority of studies on the locus of control in the context of learning are concerned with issues of learner control, this study focuses on the less-studied perspective of teacher control.

Garrison and Baynton (1987) interpreted control as an opportunity and ability to influence, direct, and determine decisions related to the educational process (Garrison \& Baynton, 1987). The concept of control in distance education has been elaborated by Moore's transactional distance theory (Moore, 1993). The theory describes the psychological distance between learners and teachers that depends on three types of variables: (1) the autonomy of learners, (2) the dialogue between teachers and learners, and (3) the course structure. The last two types of variables describe the relationship between the learner and teacher and are directly interrelated - when the structure decreases, the amount of dialogue increases and vice-versa; these changes happen dynamically to maintain the stability of a student-teacher communication system (Saba,

\footnotetext{
${ }^{1}$ http://wordpress.org/extend/plugins/lepress-20/
} 
2002). Such a dynamic shift of balance between the dialogue and the structure influences the levels of both learner and teacher control.

The locus of control becomes visible through decision-making: "who is making the choices about where to go next at any given point in a sequence of learning activities" (Dron, 2007). Learner control is an important condition for successful self-regulated learning and it is supported by the PLE. Dron noted that even when the learner chooses a particular option, this choice could still be suggested or predefined by the teacher or the software. A homework assignment is a typical case in point because deadline, format (e.g., 500 word essay), and topic are predefined by the teacher. Therefore, providing possibilities for structuring and predefining online learning activities might enhance the teacher's sense of control.

The concept of learner control is related to the approach of self-directed learning (Hiemstra, 1994; Knowles, 1975). In the case of self-directed learning, the balance of control can dynamically change between the learner and the teacher, depending on the specific situation, personal capabilities of the learner, and the readiness of the teacher to provide support (Candy, 1991). Dron illustrated the unstable nature of control by describing control as "a constant and dynamically changing variable, not just because it is a negotiable quantity, but due to the nature of people and their diverse needs as learners" (2007).

Modern learning theories promote reducing teacher control:

The locus of control in a social-constructivist system shifts somewhat away from the teacher, who becomes more of a guide than an instructor, but who assumes the critical role of shaping the learning activities and designing the structure in which those activities occur. (Anderson \& Dron, 2011)

To support the balance of control between the teacher and the learner, Candy proposed using various instructional strategies that could be placed at intervals along the learning "continuum" (1991).

For successful implementation of the formal course in the informal learning environment, learning activities that are chosen for implementation should be defined in terms of formal learning that is familiar to the teachers. Teacher control becomes apparent in the context of different teaching activities and choices (Dron, 2007) that occur over time (Figure 1). 


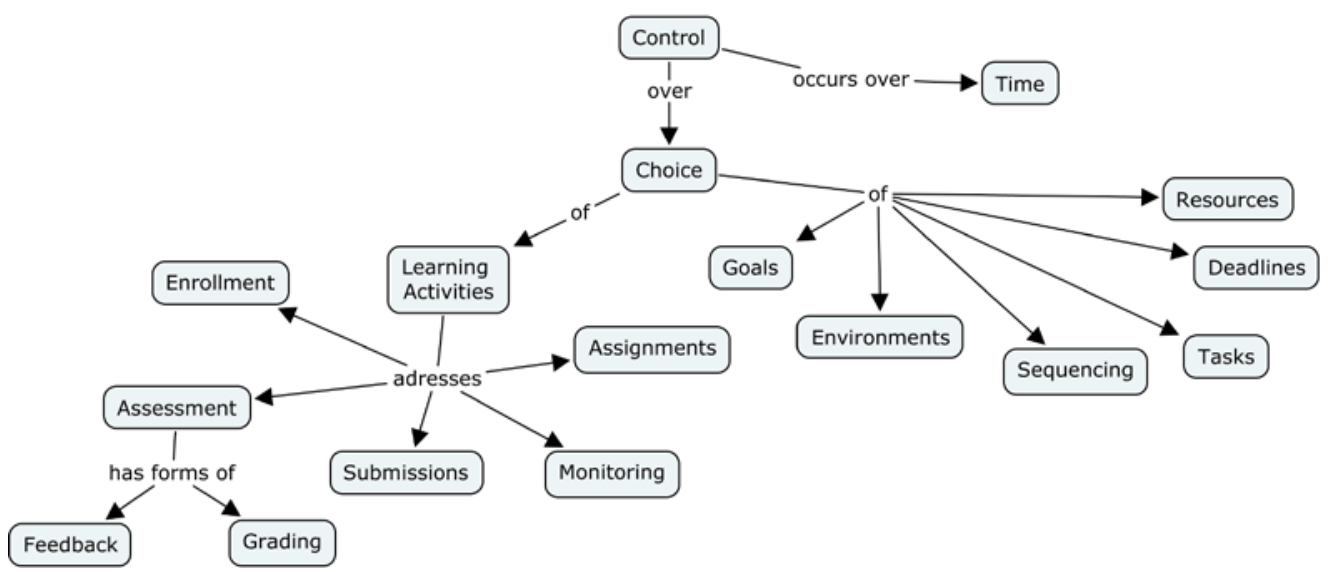

Figure 1. Model of teacher control in the context of formal learning.

The figure shows that by following Dron, we define control as choice over different learning artefacts such as tasks, resources, deadlines, and so on, and as choice of different learning activities. In the context of formal learning (even if it is carried out in an informal learning environment), teachers expect to control such learning activities as the enrolment of students into a course, official announcements, assignments, the collection and assessment of homework submissions, and the monitoring of the overall learning process in the course. Formative assessment of learning outcomes can be implemented in the form of written feedback from the teacher, while summative assessment is usually provided in the form of a grading scale.

\section{Learning Environments as Determinants for the Locus of Control}

Dron (2007, p. 12) argued that new Web 2.0 tools can never be ideal for teaching:

It would generally be difficult to base an entire sequence of learning transactions on such tools as they are unable, on their own, to perform or to support the full range of functions that might be expected of a teacher.

Some identified issues were addressed in the design of LePress.

- Loss of control. Dron and Bhattacharya identified specific issues of control over tools, services, and data. LePress serves WordPress data by maintaining learning metadata. This allows the implementation of specific learning activities that are required for formal learning. LePress also addresses concerns regarding personal data safety. For example, personal grades of students are only accessible privately. 
- Loss of monitoring. Monitoring is an opportunity of the teacher to track interactions of students. LMSs have tools for initiating, directing, and monitoring every student's action. PLEs have a bottom-up approach, where the student decides not only when and with whom to interact but also whether to make these interactions invisible to the teacher. LePress allows teachers to monitor course enrolments and submissions of homework.

- Assessment issues. In a PLE the teacher has difficulty in keeping records of students. Assessing results in dispersed blogs of students can be a timeconsuming task. LePress enables student submissions to be combined to form a class book. The teacher can access all submissions from one designated interface. The same interface can be used for proving the validity of course results by allowing an institutional auditor to verify consistency and fairness of assessments.

The structure of an environment influences the behaviour of users (Dron, 2007; Senge, 1991). Taking the previous framework of control, one can assess the impact of different learning environments on the locus of control in teaching. The teacher and the learners can have very different levels of control over the same type of choice. In a Web 2.0 learning environment the student can have almost unlimited control over the choice of goals, tasks, and resources, depending on personal experience and level of selfdirection. In contrast, the teacher has maximum control over learning activities such as course enrolments, assignments, and assessments in an LMS. Closed environments like LMSs allow limited, often predefined paths of learning. LMSs are designed to implement the requirements of institutional learning and reflect institutional structure. "Most universities and other higher education academies are natural hierarchies, with the learner at the bottom of the chain" (Dron \& Bhattacharya, 2007). Highly structured, top-down managed hierarchies in an LMS induce highly structured pedagogical behaviour, which cannot be changed by the students. In contrast, in a PLE the learner uses bottom-up design: The learners are free to adapt the system for their tasks. In Web 2.0 learning environments the user is less directed and has much more freedom of choice.

While freedom of choice supports the constructivist approach and self-regulation of learners, it conflicts with the structural requirements of formal learning and limits control by the teacher, who has no tools to implement required learning activities. Pata et al. (2012) argued that it is essential to design elements that enable self-organization of the course as an ecosystem, as well as to regain some control over what is happening in the system. Attwell (2007) also argued that there is an increasing need to formalize the outcomes of informal learning, which until recently received little attention from researchers (Attwell, 2007).

The teacher in a blog-based PLE today is not so much a designer of the environment but a fellow navigator (Bhattacharya \& Dron, 2007). Hughes (2009) proposes that teachers 
work with a set of circumstances rather than trying to control or alter them. However, in the case where students are not prepared to make use of a PLE, teacher control over the course is highly welcomed. Notice also that effective use of a blog-based course assumes certain technical skills on the part of learners and teachers as well as regular feedback to learners (Tammets \& Normak, 2012).

Based on the concept of teacher control, we designed LePress, a software solution aimed at supporting teacher control in blog-based courses. This will be presented in the next section.

\section{LePress: Sustaining Teacher Control in Blog-Based Course} Environments

Kim (2008) noted that current educational blogs are normally not customized for educational purposes in terms of user interface and functional features (Kim, 2008). LePress was designed to sustain teacher control in blog-based courses by adding some course management functionalities to WordPress. LePress is a meta-mediator, that is, it mediates the learning-related mediators (enrolment requests, participants' lists, assignments, submissions, feedback) seamlessly between the teacher's blog and the blog-based PLEs of learners (See Figure 1).

LePress is an add-on module (plug-in) installed on top of WordPress that makes use of a subset of native interface elements, communication protocols, and other features of WordPress with minor user interface enhancements (additional submenu on WordPress dashboard, additional checkbox in blog post editing view, front-end widget).

In Figure 2 the front-end widgets for the teacher (a) and for the student (b) are shown. While all learning activities provided by LePress are available through a WordPress dashboard, these widgets allow course participants to interact with the course directly in the blog web-page. Using the widget, the students can select the required course and register instantly. 


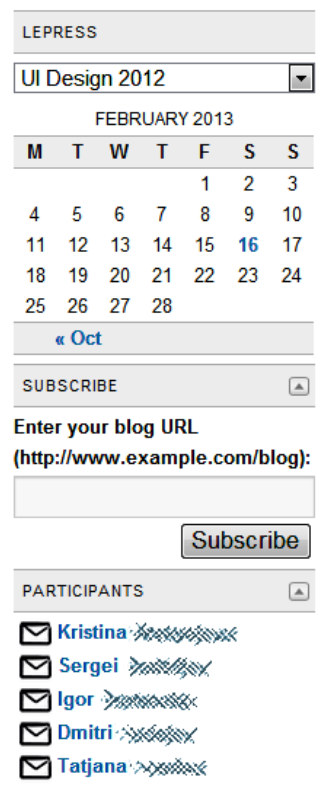

a)

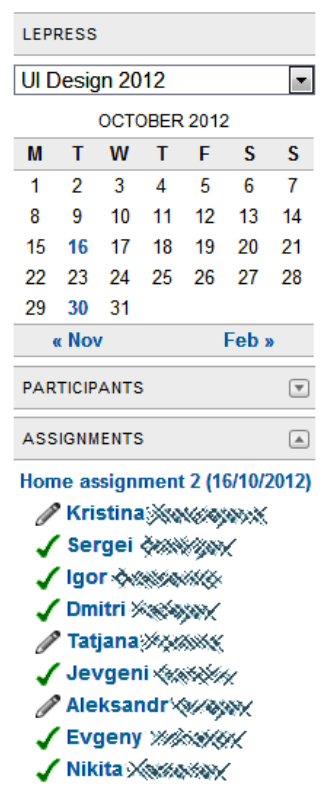

b)

Figure 2. LePress sidebar widgets for a student (a) and for a teacher (b) (family names are shaded).

Besides a calendar showing deadlines for submissions, the teacher and the students have access to a list of the course participants, which refers to students' homepages and email addresses. Students can immediately subscribe to the course by entering the URL address of their own blog, or in the case where they are already logged in, just by clicking the "Subscribe" button. The students can initiate a homework submission by selecting an appropriate assignment in an "Assignments" list. In turn, the teacher can use the "Assignments" list to view the names of students who have already begun an assignment.

While use of blogs in education makes the assumption of group work based on communications of students, the focus of the current study is limited to teacher-student relationships. There are certain design approaches that could support group-based assessments in the blogs, but these functionalities are planned for future development. Nevertheless, there are other research and development activities that can be used for this purpose. One example is the software project EduFeedr, which allows monitoring of the feedback given by one student to another (Põldoja, Savitski, \& Laanpere, 2010; Põldoja \& Laanpere, 2009).

LePress is designed with the aim of implementing workflow that is the least disruptive to the existing blogging workflow of WordPress. While LePress adds some learningrelated features to WordPress, all the original publishing functionalities of WordPress remain intact after installing the LePress plug-in. 
LePress shares some characteristics of a course coordination space as suggested by Wilson (2007). Figure 3 shows how LePress coordinates what we call learning flow between blogs of teachers and students involved in the course. The diagram illustrates the learning flow between the teacher and the student. Both participants have LePress installed in their personal WordPress blogs. As shown in Figure 3, WordPress is used for implementing existing blogging activities like posting and commenting. LePress adds learning semantics to these activities and turns traditional blog communication flow into learning workflow.

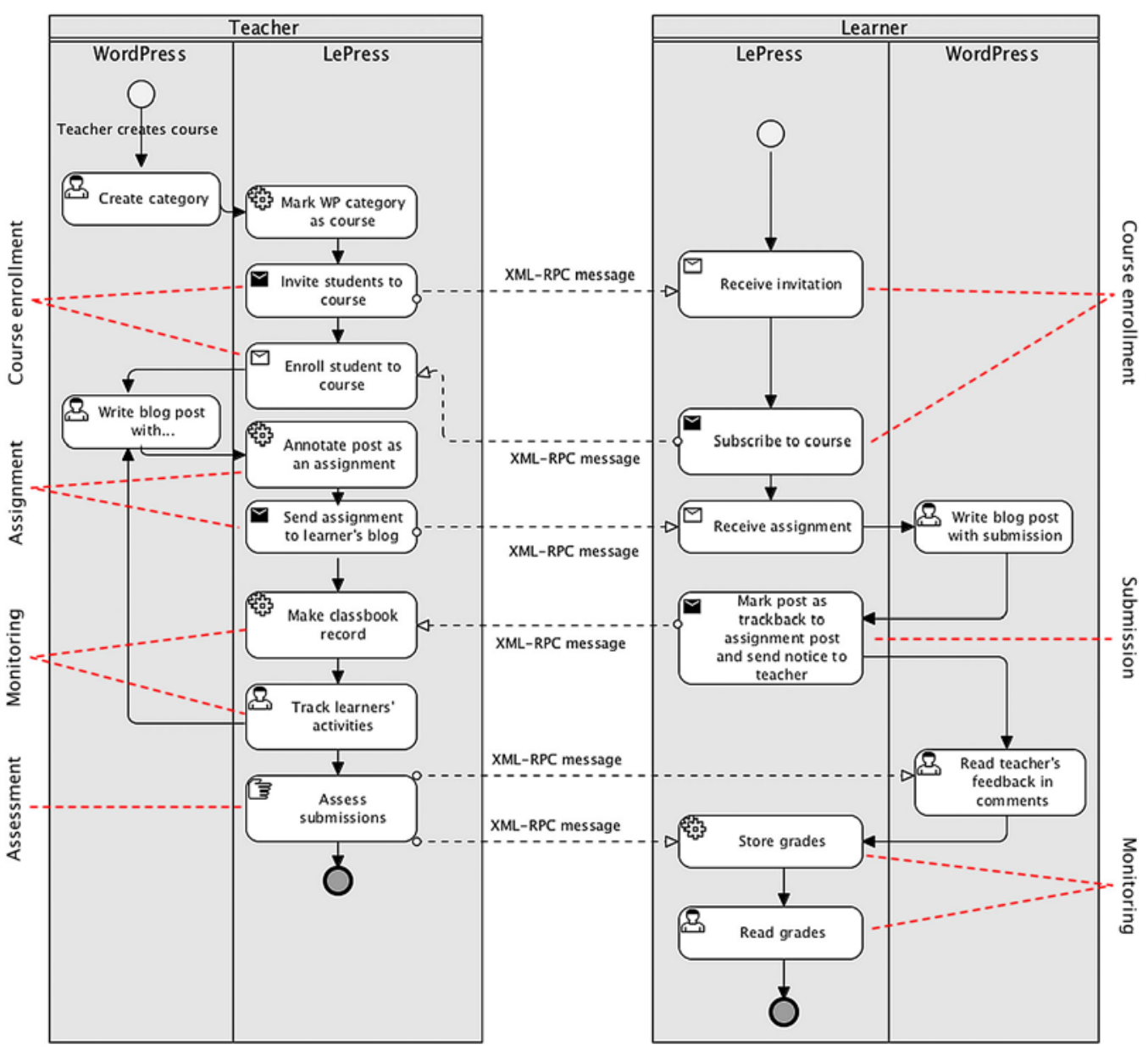

Figure 3. Learning activities of LePress.

LePress specifically adds several functionalities to WordPress to address challenging issues related to teacher control (see Figure 1) in an existing blog-based environment. Any WordPress category in the blog of the teacher can be marked as a course, allowing the teacher to organize course activities and learning content around it. Using LePress, the teacher can enrol students in a course in an open or controlled manner, turn any blog post into an assignment, set submission deadlines, monitor submissions of students, provide formative assessments in the form of feedback using the WordPress 
comment field, and provide summative assessments using the LePress private grading system. LePress also enhances the productivity of teachers by allowing them to save course content as a template and to reuse it in future courses.

LePress is positioned as a tool, which can balance control between the teacher and the learner in PLE. In Figure 4, a diagram is presented that illustrates the speculative distribution of control between teacher and student (horizontal axis) in different learning environments. The vertical axis shows the structure to dialogue ratio, where we consider the amount of dialogue proportional to the amount of choice, as proposed by Dron (2007). This picture is intended to situate LePress in the context of other popular tools. In addition, this diagram illustrates the role that learning environments play in the distribution of control between teacher and learner.

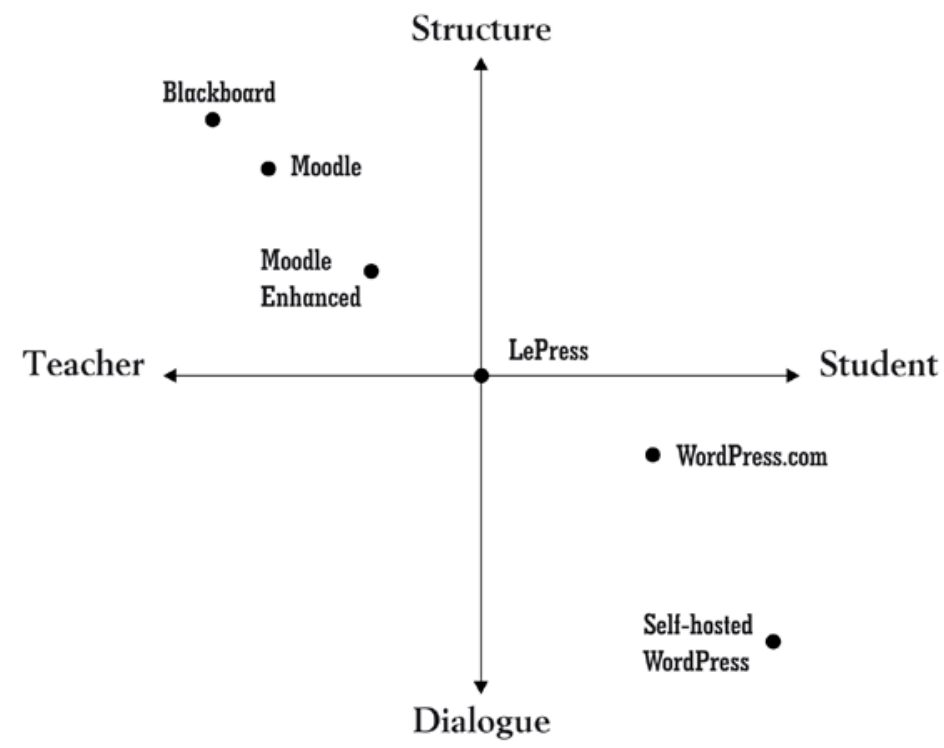

Figure 4. Speculative distribution of control over learning flows between the teacher and the student in different learning environments.

A comparison is made here of several environments that have different levels of structure and dialogue. In the top left corner Blackboard LMS is placed as the most structured and the least controlled by the student environment. Blackboard is a closed environment based on proprietary software. There is only a minimum amount of customizing of the environment available and only for the teachers. All learning flows are strictly predefined and cannot be modified. Another example of the traditional LMS is Moodle, which is a less structured and a more open environment that is more adaptable to students' needs. Thanks to open source code and the extendable architecture of Moodle, possibilities for customization increase dramatically by means of plug-ins. Lots of Moodle plug-ins have been developed that allow the use of different forms of dialogue between the teacher and the learner (e.g., a blog plug-in, which gives students more control). 
The authors consider a blog installed on the wordpress.com platform as a tool that provides more possibilities for dialogue, thereby shifting control to the student's side; thus it can be used as a PLE. However, the hosting policies of wordpress.com are very strict concerning the installation of plug-ins and therefore the possibilities for customization of the environment and the adaptation of it to learning flows are limited. These limitations do not apply when using the self-hosting WordPress blog, because many diverse plug-ins are available. In this situation, the student has almost unlimited possibilities for customization and almost full control over the environment. At the same time, the amount of teacher control vanishes.

LePress is intended as an add-on to the self-hosted WordPress blog. It provides the teacher with more control over the dialogue by providing control over feedback, assessment, and grading. As the diagram shows, LePress balances control between the teacher and the student and between structure and dialogue.

The authors conducted a survey to examine both usability and perceived teacher control in a course in which LePress had been used. The results of this study are presented in the following sections.

\section{A Survey on Perceived Teacher Control Using LePress}

The development of LePress has been accompanied by iterative design-based research (DBR) (Barab \& Squire, 2004; Sandoval \& Bell, 2004; Van den Akker, Gravemeijer, McKenney, \& Nieveen, 2006; Wang \& Hannafin, 2005).

According to Banathy (1996), in design science "methods are tools for creating and changing human artefacts" (Banathy, 1996). An artefact created as a result of a pedagogical design study could be, for instance, a piece of educational software, digital content, curriculum, or a project. DBR is often used for research in learning environments. The main goal of such research is not the production of a software product per se, but rather that the exploration of research questions about learning or teaching are reified, explored, and tested by the design and use of the software/learning environment (Kelly, 2006).

Several different pedagogical and technological questions relating to the design of LePress have been examined in previous iterations. These include the problem statement and idea (Tomberg \& Laanpere, 2008), issues of semantic interoperability (Tomberg \& Laanpere, 2009), technological implementation of test-based assessments in a blog-based environment (Tomberg, Kuli, Laanpere, \& Normak, 2010), and the design of learning workflow and semantics (Tomberg, Laanpere, \& Lamas, 2010). Each result was the basis for another iteration of redesigning LePress. In the current iteration, the authors focused on the perceptions of teacher control in PLEs that are enhanced by LePress. The results of this study could be reused in designing not only the 
next version of LePress but, more importantly, could address the impact of learning environments on teacher control in a more general sense.

\section{Research Questions and Design}

A questionnaire was designed that asked teachers for their perception of the amount of control they felt they had when using LePress as compared to teaching in blog-based learning environments. They were also asked for their perception of the usability and ease of use of LePress.

The reason for focusing on usability is that perceived ease of use is assumed to be one of the main determinants of intention to use, and the future adoption of, an eLearning system (Davis, 1989; Hu, Clark, \& Ma, 2003; Teo, 2009; Teo, Lee, \& Chai, 2008). This is especially relevant for PLEs as there is usually a much higher degree of freedom and choice for teachers to adopt them or not. Accordingly, Gillet (2010) noted usability as one of the most challenging features of a PLE (Gillet, 2010). Clearly, any solution that is designed as a superstructure over a PLE, such as LePress, needs a critical level of usability and learnability. The additional superstructures require users to change their habitual patterns of using the software and extra effort is required when learning new features. In cases where the software is too complex, teachers will not adopt it.

The authors hypothesized the following: (1) LePress would be perceived as easy to use by its users, and (2) LePress would be perceived as enabling a higher degree of teacher control. Finally, in order to establish the importance of teacher control in the context of online learning, it was also hypothesized that (3) perceived teacher control would be a significant factor to contribute to perceived ease of use.

\section{Participants}

The sample of this study consisted of 37 teachers (30 female and 7 male) from different Estonian K-12, vocational, and higher education institutions. The sample was relatively homogenous concerning their prior e-learning experience, related attitudes, and behaviour. Their teaching experience was between 1 and 34 years (median 18 years). Seven teachers had already used LePress before in more than one of their regular courses within the last year. The rest of the respondents had participated in a 6-month staff-training programme, where they actively used LePress. Twenty-nine respondents had prior experience of teaching with traditional blogs. Therefore, they were well able to compare teaching with and without LePress in a blog-based PLE.

\section{Questionnaire}

A questionnaire was created consisting of two demographic, 26 Likert scale, 16 multiple choice, and two open response questions. An online questionnaire was implemented in the Estonian language using an open-source survey tool called Limesurvey ${ }^{2}$. The items

\footnotetext{
${ }^{2}$ http://www.limesurvey.org/
} 
were grouped into three parts: respondent's background information, perceived usability of LePress, and perceived teacher control in LePress.

The second part of the questionnaire focused on the usability of LePress and consisted of three sub-groups:

1. The items related to the usability of LePress in general (e.g., "The user interface of LePress is intuitive");

2. The items related to affordances of LePress regarding learning and teaching tasks (e.g., "I don't mind if assignments are submitted as blog posts");

3. The items related to perceived ease of use of LePress with specific learning activities (e.g., "Assessment of students' submissions is easy in LePress").

In the last part of the questionnaire, respondents were asked to assess the perceived level of teacher control in LePress in comparison to blogs without LePress. The respondents were asked to indicate their agreement or disagreement with six claims on a 5-step Likert scale. One of these claims was generic ("LePress enhances teacher's control over the course"), while others focused on specific aspects of teacher control (e.g., "LePress enhances teacher's control over course enrolments”).

\section{Procedure}

One week after completion of the staff-training programme, the participants were then asked by email to complete the online questionnaire anonymously during a one-week period. Forty-two requests were issued; after one week, 37 surveys had been completed online. Following that, the data was pre-processed and analysed using MS Excel and SPSS software.

Only very few teachers completed the open questions, so these revealed little further qualitative insight. Therefore, the results are not reported here.

\section{Results}

The following section examines the results pertaining to the following three hypotheses:

1. LePress is perceived as easy to use by its users,

2. LePress enables a higher degree of teacher control, and

3. Perceived teacher control significantly contributes to perceived ease of use. 


\section{Perceived Ease of Use}

LePress has gone through a number of design iterations. Within these iterations, considerable feedback has been taken into account in order to improve the perceived ease of use of the software. To validate the hypothesis, eight items were included to measure perceived ease of use (Cronbach $\alpha=0.840$ ). Each item was answered on a fivepoint Likert scale with a neutral midpoint (0) and two levels of agreement $(1,2)$ and disagreement $(-1,-2)$.

The eight items were included in a composite variable, perceived ease of use (mean $=$ 0.78 , std $=0.54, \mathrm{n}=36$ ). A one-sample t-test indicated that the mean was significantly higher than the neutral midpoint $(\mathrm{t}=8.68, \mathrm{df}=35$, $\mathrm{p}$ one-tailed $<0.0001$ ).

For each of the eight items, one-sample t-test was then performed to check for significant differences to the neutral midpoint. For these analyses, one-tailed tests were performed and the critical alpha level was adjusted according to the Bonferroni correction $\left(\alpha_{\text {crit }}=0.00625\right)$ to take into account the multiple tests performed. Table 1 shows the results of these analyses. Six of the eight scales give a significant value difference, while two do not reach critical p levels (The user interface of LePress is intuitive and creating a new course is an easy task in LePress).

We conclude from these results that users perceive LePress as being easy to use. The detailed analyses also show that it is perceived to be easy to learn and user-friendly and that it is easy to add students, to give assignments, to find submissions, and to assess students' work. This is remarkable since new software is often judged as being more difficult to use than the customary software to which it is compared.

Table 1

Perceived Ease of Use of LePress by Teachers

\begin{tabular}{|l|c|c|c|c|c|}
\hline & $\mathrm{n}$ & Mean & $\begin{array}{c}\text { Std. } \\
\text { Dev. }\end{array}$ & $\mathrm{t}$ & $\mathrm{p}^{*}$ \\
\hline $\begin{array}{l}\text { Perceived ease of use } \\
\text { (Composite value) }\end{array}$ & 36 & 0.78 & .540 & $\begin{array}{c}8.68 \\
0\end{array}$ & $<0001$ \\
\hline LePress is easy to learn for a novice teacher & 35 & 0.89 & .676 & 7.750 & $<0001$ \\
\hline LePress is user-friendly & 35 & 0.86 & .733 & 6.915 & $<0001$ \\
\hline The user interface of LePress is intuitive & 30 & 0.37 & .765 & 2.626 & .0067 \\
\hline $\begin{array}{l}\text { Creating a new course is an easy task in } \\
\text { LePress }\end{array}$ & 25 & 0.48 & .918 & 2.613 & .0076 \\
\hline $\begin{array}{l}\text { Addding a student to a course is an easy task in } \\
\text { LePress }\end{array}$ & 25 & 0.80 & .764 & 5.237 & $<0001$ \\
\hline $\begin{array}{l}\text { Giving assignments for students is an easy task } \\
\text { in LePress }\end{array}$ & 27 & 0.89 & .801 & 5.769 & $<0001$ \\
\hline $\begin{array}{l}\text { It is easy to find the students' submissions in } \\
\text { LePress }\end{array}$ & 33 & 1.06 & .788 & 7.730 & $<0001$ \\
\hline $\begin{array}{l}\text { Assessment of students' submissions is easy in } \\
\text { LePress }\end{array}$ & 27 & 0.78 & .934 & 4.328 & $<0001$ \\
\hline
\end{tabular}

* one-tailed, adjusted $\alpha_{\text {crit }}=0.00625$ 


\section{Perceived Teacher Control}

The second hypothesis was that users would perceive LePress as enhancing teacher control over the course. Five items (Cronbach $\alpha=0.891$ ) asked users to estimate their level of control of blog-based courses. Again, each item was answered on a five-point Likert Scale with a neutral midpoint (0) and two levels of agreement $(1,2)$ and disagreement $(-1,-2)$.

The five items were included in a composite variable, perceived teacher control (mean $=$ 1.06, std $=0.65, \mathrm{n}=33$ ). A one-sample $\mathrm{t}$-test indicated that the mean was significantly higher than the neutral midpoint $(t=9.386, \mathrm{df}=32$, p one-tailed $<0.0001)$.

As in the case of perceived ease of use, a one-sample t-test was performed for each of the five items. For these analyses, one-tailed tests were performed and the critical alpha level was adjusted according to the Bonferroni correction $\left(\alpha_{\text {crit }}=0.01\right)$. Table 2 shows that means in all scales were significantly higher than the neutral midpoint.

We conclude that LePress is perceived to increase teachers' opportunities to exert control in the course. Users were in considerable agreement that LePress improves control over the course and enrolments, enhances the monitoring of activities, and gives a better overview of assignments, feedback, and grades.

Table 2

Perceived Teacher Control Results

\begin{tabular}{|l|c|c|c|c|c|}
\hline & $\mathrm{n}$ & Mean & Std. Dev. & $\mathrm{t}$ & $\mathrm{p}$ \\
\hline $\begin{array}{l}\text { Perceived teacher control } \\
\text { (Composite value) }\end{array}$ & 33 & 1.06 & .647 & 9.386 & $<0001$ \\
\hline $\begin{array}{l}\text { LePress enhances teacher's control over the } \\
\text { course }\end{array}$ & 28 & 1.04 & .744 & 7.362 & $<0001$ \\
\hline $\begin{array}{l}\text { LePress enhances monitoring of course } \\
\text { activities }\end{array}$ & 29 & 1.21 & .675 & 9.628 & $<0001$ \\
\hline $\begin{array}{l}\text { LePress gives students better overview of } \\
\text { assignments }\end{array}$ & 32 & 1.16 & .954 & 6.855 & $<0001$ \\
\hline $\begin{array}{l}\text { LePress shows grades and feedback to } \\
\text { students in more convenient way }\end{array}$ & 33 & 1.18 & .846 & 8.02 & $<0001$ \\
\hline $\begin{array}{l}\text { LePress enhances teacher's control over } \\
\text { course enrollments }\end{array}$ & 23 & 0.83 & .834 & 4.750 & $<0001$ \\
\hline
\end{tabular}

$*$ one-tailed, adjusted $\alpha_{\text {crit }}=0.01$ 


\section{Perceived Teacher Control Increases Perceived Ease of Use}

The results so far indicate that LePress has good usability and increases the teacher's control during the course. The last hypothesis will attempt to establish that there is a relationship between these variables. If perceiving higher control leads to higher ease of use, then this will also lend credence to the assumption that teacher control is an important factor in how favourably learning software is judged by teachers and, hence, how likely it is that they will adopt LePress in their course.

The validity of this hypothesis was tested by performing a linear regression analysis. The independent variables were the five items from the perceived teacher control scale. The dependent variable was the composite variable, perceived ease of use. The linear regression with all the predictors entered into the model gave a highly significant result ( $F=5.226, p=0.005)$ with an overall $R=0.788\left(R^{2}=0.620\right)$. A stepwise regression shows that the item LePress enhances teacher's control over the course is the most important predictor. When only this variable is entered into the model, the model is significant $(F=21.20, p<0.001)$ with an overall $R=0.717\left(R^{2}=0.515\right)$. Due to the high inter-correlation of the items, the rest of the items do not add any significant amount of predictive variance to the model. The two items that come the closest to being entered as well are (a) LePress enhances teacher's control over course enrolments ( $\beta=0.384$, $p$ $=0.053$ ) and (b) LePress shows grades and feedback to students in a more convenient way ( $\beta=0.310, p=0.075$ ). This could be interpreted as meaning that teachers placed special importance on being able to control enrolments and grades when judging ease of use. However, due to the high inter-correlations of predictors, beta weights should be interpreted with caution, and additional research is needed to establish the relative importance of different factors of teacher control for judging ease of use.

\section{Conclusion}

The students and teachers continue to escape from walled gardens of institutional learning environments to the "Web 2.0 jungle" (Dron \& Bhattacharya, 2007). They like to use new services with elements of social media, improved usability, and extensive learning content. The amount of learner control goes up at the expense of a lower level of teacher control. An effect of these circumstances is the inability of teachers to control learning activities that are required in the context of formal institutional learning.

This study tested three hypotheses about the course management plug-in, LePress, for use on the WordPress blog platform:

1. LePress would be perceived easy to use by its users;

2. LePress would be perceived as enabling a higher degree of teacher control; and

3. Perceived teacher control would contribute to perceived ease of use. 
We found that teachers perceive LePress as being easy to use. Teachers consider creating a new course, adding a student to a course, giving assignments, finding the students' submissions, and making assessments of students' submissions as easy tasks when using LePress. They also consider LePress as easy to learn for a novice teacher, user-friendly, and intuitive.

While there are several other studies that are concerned with issues of learner control in the context of self-directed distance learning, this study explored the issue of teacher control in blog-based distributed environments. Today teachers and educational institutions are facing a choice between closed institutional LMSs and distributed, open, weakly controlled, but very powerful PLEs based on Web 2.0. This study shows that teachers who move to blog-based PLEs can be supported by designing additional features in a PLE that sustain their control over learning activities.

The results show that specifically designed lightweight software tools like LePress can be used for coordinating courses taught in a PLE in a formal education context. When allowing the learners to use available resources in Web 2.0 environments, metamediator tools like LePress could help teachers sustain a feeling of control over managing the course activities. Additional results show that this may be especially so for less experienced teachers. We observed a negative correlation $(\mathrm{r}=0.334, \mathrm{p}<0.01)$ between teaching experience and the inclination of the teacher to teach using blogs, and a positive correlation $(0.395, \mathrm{p}<0.01)$ between the inclination of the teacher to teach using blogs and the belief that LePress enhances teacher control over the course. We assume that teachers with shorter teaching experience perceive LePress to be more helpful which in turn increases their inclination to teach with blog-based environments. It is likely that teachers with longer teaching experience have developed alternative methods to control the course workflow.

We also found evidence that teacher control is an important factor in determining how favourably learning software is judged by teachers. The regression model has substantiated the perception of control as an important predictor of ease of use. Following the claims and research of the technology acceptance model (Liao \& Lu, 2008; Ma, Andersson, \& Streith, 2005), it is assumed, therefore, that teacher control will also be a key factor in determining the adoption of LePress and the intention to use it continuously. While the latter should be subject to further research, it has become evident that teacher control is an important factor to be considered by designers in the future development of PLE.

Clearly, there are other actors besides teachers and learners who are involved in control over choice in the context of formal learning. Garrison and Baynton (1987) considered teacher, student, and content as the transactional elements that determine the balance of control. Dron (2007) extended this list by adding the group of students as a separate element, arguing that a group can have a different amount of control compared to individual members (Dron, 2007). We would argue that in addition to these elements, 
the technical environment used for course management constitutes an element that needs to be considered. Another important element that is seldom considered is the level of control exerted by the national educational policy on stakeholders. While this element is not the most prominent, it still defines many rules that the teachers and the learners must abide by. The role of the national educational policy makers as the stakeholders in control corresponds with Dron's (2007) ideas about different levels of scale as it relates to control. We consider this topic as one of interest for future research. Understanding new ways of supporting control can help in the development of dedicated tools for administrators or dashboards for universities since these could track the success of implementing education policies.

The next steps in the research are experimental and ethnographic studies. These could help to investigate typical learning activity flows and specific needs of teachers in personal learning environments and support better scaffolding of learners while retaining opportunities for implementing formal institutional requirements.

\section{Acknowledgements}

This study was funded by the targeted research grant No. 0130159s08 from the Ministry of Education and Research of the Republic of Estonia. 


\section{References}

Anderson, T., \& Dron, J . (2011). Three generations of distance education pedagogy. International Review of Research in Open and Distance Learning, 12(3), 8097. Retrieved from http:// www.irrodl.org/index.php/irrodl/article/ view/ 890/1724

Attwell, G. (2007). Personal learning environments - the future of eLearning? Lifelong Learning, 2(J anuary), 1-8.

Banathy, B. H. (1996). Designing social systems in a changing world. Springer.

Barab, S., \& Squire, K. (2004). Design-based research: Putting a stake in the ground. J ournal of the Learning Sciences, 13(1), 1- 14.

Bhattacharya, M., \&Dron, J . (2007). Cultivating the Web 2.0 jungle. Seventh IEEE International Conference on Advanced Learning Technologies, IEEE.

Candy, P. C. (1991). Self-direction for lifelonglearning. A comprehensive guide to theory and practice. In A. B. Knox, (Ed.), Higher and adult education series (p. 567). San Francisco, CA: J ossey-Bass

Clark, W., Logan, K., Luckin, R., Mee, A., \&Oliver, M. (2009). Beyond Web 2.0: Mapping the technology landscapes of young learners. J ournal of Computer Assisted Learning, 25(1), 56- 69.

Cole, M. (2009). Using Wiki technology to support student engagement: Lessons from the trenches. Computers \& Education, 52(1), 141- 146. doi:10.1016/j.compedu.2008.07.003

Conole, G., \&Alevizou, P. (2010). A literature review of the use of Web 2.0 tools in higher education (A report commissioned by the Higher Education Academy). Walton Hall, Milton Keynes, UK.

Crook, C. (2012). The "digital native" in context: Tensions associated with importing Web 2.0 practices into the school setting. Oxford Review of Education, 38(1), 63-80.

Davis, F. D. (1989). Perceived usefulness, perceived ease of use, and user acceptance of information technology. MIS quarterly, 13(7), 319-340.

Drexler, W. (2010). The networked student model for construction of personal learning environments: Balancing teacher control and student autonomy. Australasian J ournal of Educational Technology, 26(3), 369-385.

Dron, J . (2007). Control and constraint in e-learning: Choosing when to choose (Vol. 11). Hershey PA: Idea Group Publishing. 
Dron, J ., \& Bhattacharya, M. (2007). Lost in the Web 2.0 jungle. In J . M. Spector, D. G. Sampson, T. Okamoto, Kinshuk, S. A. Cerri, M. Ueno, \&A. Kashihara (Eds.), ICALT (pp. 895- 896). IEEE Computer Society.

Garrison, D. R., \& Baynton, M. (1987). Beyond independence in distance education: The concept of control. American J ournal of Distance Education, 1(3), 3- 15.

Gillet, D. (2010) Personal learning environments in a global higher engineering education Web 2.0 realm. IEEE EDUCON Education Engineering 2010 Conference, Madrid.

Greenhow, C., Robelia, B., \&Hughes, J . E. (2009). Learning, teaching, and scholarship in a digital age: Web 2.0 and classroom research: What path should we take now? Educational Researcher, 38(4), 246- 259.

Hiemstra, R. (1994). Self-directed learning. In B. Rothwell \& K. J . Sensenig (Eds.), The sourcebook for self-directed learning. Amherst, MA: HRD Press

Hu, P. Clark, T., \& Ma, W. (2003). Examining technology acceptance by school teachers: A longitudinal study. Information \& Management, 41(2), 227-241.

Hughes, A. (2009). Higher education in a Web 2.0 world. Retrieved from http:// www.jisc.ac.uk/publications/generalpublications/2009/heweb2.aspx

Kaschig, A. Maier, R. Sandow, A., Brown, A., Ley, T., Magenheim, J ., Mazarakis, A. et al, (2012). Technological and organizational arrangements sparking effects on individual community and organizational learning. Proceedings of the 7th European Conference on Technology-enhanced Learning. Heidelberg: Springer.

Kelly, A. E. (2006). Quality criteria for design research. In J . Van den Akker, K. Gravemeijer, S. McKenney \&N. Nieveen (Eds.), Educational design research (pp. 107- 118). Taylor \& Francis Ltd.

Kim, H. N. (2008). The phenomenon of blogs and theoretical model of blog use in educational contexts. Computers \& Education, 51(3), 1342- 1352. doi:10.1016/j.compedu.2007.12.005

Knowles, M. S. (1975). Self-directed learning. New York: Association Press.

Lee, M. J ., \& McLoughlin, C. (2007). Teaching and learning in the Web 2.0 era: Empowering students through learner-generated content. International J ournal of Instructional Technology and Distance Learning, 4(10), 21- 43. 
Liao, H.-L., \& Lu, H.-P. (2008) The role of experience and innovation characteristics in the adoption and continued use of e-learning websites. Computers \& Education, 51(4), 1405- 1416. doi:10.1016/j.compedu.2007.11.006

Ma, W. W., Andersson, R., \& Streith, K. O. (2005). Examining user acceptance of computer technology: An empirical study of student teachers. J ournal of Computer Assisted Learning, 21(6), 387- 395. doi:10.1111/j.13652729.2005.00145.x

McLoughlin, C., \&Lee, M. J . (2007). Social software and participatory learning: Pedagogical choices with technology affordances in the Web 2.0 era. In ICT: Providing choices for learners and learning, Proceedings ascilite Singapore 2007 (pp. 664-675).

Meccawy, M., Blanchfield, P., Ashman, H., Brailsford, T., \& Moore, A. (2008). WHURLE 2.0: Adaptive learning meets Web 2.0. In P. Dillenbourg \& M. Specht (Eds.), Times of Convergence, Technologies Across Learning Contexts. Lecture Notes in Computer Science (Vol. 5192, pp. 274- 279). Heidelberg/ Berlin: Springer.

Moore, M. G. (1993). Theory of transactional distance. In D. Keegan (Ed.) Theoretical principles of distance education (pp. 22-38). New York: Routledge.

Pata, K., Laanpere, M., \&Normak, P. (2012). The ecology for open online courses. Manuscript in preparation

Pata, K., \& Merisalo, S. (2009). Self-direction indicators for evaluating the design-based e-learning course with social software. In Kinshuk, D. G. Sampson, J . M. Spector, P. Isaías \& D. Ifenthaler (Eds.), IADIS International Conference on Cognition and Exploratory Learning in Digital Age (CELDA 2009) (pp. 196203). IADIS Press.

Põldoja, H., Savitski, P., \&Laanpere, M. (2010, September). Aggregating student blogs with EduFeedr. Lessons learned from first tryouts. In Proceedings of the 3rd Workshop on Mashup Personal Learning Environments, in conjunction with the 5th European Conference on Technology-Enhanced Learning (ECTEL'10). Barcelona, Spain.

Põldoja, H., \&Laanpere, M. (2009). Conceptual design of edufeedr-an educationally enhanced mash-up tool for agora courses. In Mash-Up Personal Learning Environments-2st Workshop MUPPLE (Vol. 9)

Redecker, C., Ala-Mutka, K. Bacigalupo, M., Ferrari, A., \&Punie, Y. (2009). Learning 2.0: The impact of Web 2.0 innovations on education and training in Europe (Final report). Seville : European Commission-J oint Research Center-Institute for Porspective Technological Studies. 
Saba, F. (2002). Evolution of research in distance education: Challenges of the online distance learning environment. Paper presented at the Second Conference on Research in Distance and Adult Learning in Asia, The Open University of Hong Kong.

Safran, C., Helic, D., \&Gütl, C. (2007). E-Learning practices and Web 2.0. Proceedings of the International Conference of'Interactive computer aided learning ICL2007: EPortfolio and Quality in e-Learning (Vol. 1, pp. 1-8).

Salinas, J., Marín, V., \& Escandell, C. (2011). A case of an institutional PLE: Integrating VLEs and e-portfolios for students. The PLE Conference 2011.

Sandoval, W. A., \& Bell, P. (2004). Design-based research methods for studying learning in context: Introduction. Educational Psychologist, 39(4), 199- 201.

Sankey, M., \& Huijser, H. (2009). A “likely benefit” from aligning Web 2.0 technologies with an institutions learning and teaching agenda. In T. Bastiaens, J. Dron \& C. Xin (Eds.), Proceedings of World Conference on E-Learning in Corporate, Government, Healthcare, and Higher Education (pp. 3686- 3695). Chesapeake, VA: AACE: Association for the Advancement of Computing in Education (AACE).

Schmidt, A., Hinkelmann, K., Ley, T., Lindstaedt, S. Maier, R., \& Riss, U. (2009). Conceptual foundations for a service-oriented knowledge and learning architecture: Supporting content, process and ontology maturing. In T. Pellegrini, S. Auer, K. Tochtermann \& S. Schaffert (Eds.), Networked knowledge - networked media (Vol. 221, pp. 79-94). Berlin / Heidelberg : Springer.

Senge, P. M. (1991). The fifth discipline, the art and practice of the learning organization. Performance + Instruction, 30(5), 37. doi:10.1002/pfi.4170300510

Siemens, G. (2006). Learning or management systems. Retrieved from http:// www.connectivism.ca/ ?p=243

Steel, C., \&Levy, M. (2009). Creativity and constraint: Understanding teacher beliefs and the use of LMS technologies. In R. Atkinson \& C. McBeath (Eds.), Same places, different spaces: Proceedings of ascilite Auckland 2009. 26th Annual ascilite International Conference, Auckland, New Zealand (pp. 1013- 1022), Auckland.

Tammets, K., \& Normak, P. (2012). Learning outcomes for blog-based courses: A case study. OST'12: Open and Social Technologies for Networked Learning, Tallinn. New York: Springer-Verlag. 
Teo, T. (2009). Modelling technology acceptance in education: A study of pre-service teachers. Computers \&Education, 52(2), 302-312.

Teo, T., Lee, C., \& Chai, C. (2008), Understanding pre-service teachers' computer attitudes: applying and extending the technology acceptance model. J ournal of Computer-Assisted Learning, 24(2), 128- 143.

Tomberg, V., Kuli, R., Laanpere, M., \& Normak, P. (2010). Delivering QTI self-tests to personal learning environments using Wookie widgets. In X. Luo, M. Spaniol, L. Wang, Q. Li, W. Nejdl, \& W. Zhang (Eds.), Advances in Web-Based Learning ICWL 2010 (Vol. 6483, pp. 250- 258). Springer Berlin / Heidelberg

Tomberg, V., \& Laanpere, M. (2008). Towards lightweight LMS 2.0: A blog-based approach to online assessment. Times of Convergence, Technologies Across Learning Contexts (pp. 431-436).

Tomberg, V., \&Laanpere, M. (2009). RDFa versus Microformats : Exploring the potential for semantic interoperability of mash-up personal learning environments. In F. Wild, M. Kalz, M. Palmér \& D. Müller, (Eds.), CEUR Workshop Proceedings (Vol. 506, pp. 102-109).

Tomberg, V., Laanpere, M., \& Lamas, D. (2010). Learning flow management and semantic data exchange between blog-based personal learning environments. HCI in Work and Learning, Life and Leisure (pp. 340-352).

Ullrich, C., Borau, K., Luo, H., Tan, X., Shen, L., \& Shen, R. (2008). Why Web 2 . 0 is good for learning and for research : Principles and prototypes. Proceedings of the 17th international conference on World Wide Web (pp. 705- 714). New York, NY, USA: ACM.

Van den Akker, J ., Gravemeijer, K., McKenney, S., \&Nieveen, N. (2006). Educational design research, chemistry \& biodiversity (Vol. 1, pp. 1829-1841). New York: Taylor \& Francis.

Wang, F., \& Hannafin, M. J . (2005). Design-based research and technology-enhanced learning environments. Educational Technology Research and Development, 53(4), 5- 23.

Wilson, S. (2007). PLEs and the institution. Scott's Workblog. Retrieved from http:// zope.cetis.ac.uk/ members/ scott/ blogview?entry=20071113120959

Zimmerman, B. J . (1990). Self-regulated learning and academic achievement: An overview. Educational psychologist, 25(1), 3- 25. 
Zourou, K. (2012). On the attractiveness of social media for language learning: A look at the state of the art. Alsic. Apprentissage des Langues et Systèmes d'Information et de Communication, 15(1).

\section{Athabasca University $\mathbf{T}$}

(C) (i)

